\title{
Size-resolved global emission inventory of primary particulate matter from
} energy-related combustion sources

${ }^{a}$ Energy Systems Division, Argonne National Laboratory, Argonne, IL 60439, USA

${ }^{b}$ Department of Civil and Environmental Engineering, University of Illinois at Urbana-

${ }^{c}$ School of the Environment, Nanjing University, Nanjing, 210046, PR China Argonne National Laboratory (“Argonne”). Argonne, a U.S. Department of Energy Office of Science laboratory, is operated under Contract No. DE-AC02-06CH11357. The U.S. Government retains for itself, and others acting on its behalf, a paid-up nonexclusive, irrevocable worldwide license in said article to reproduce, prepare derivative works, distribute copies to the public, and perform publicly and display publicly, by or on behalf of the Government.

22 *Corresponding author. Energy Systems Division, Argonne National Laboratory, Argonne, IL 23 60439, USA. Tel.: +1 6302522413

24 E-mail address: fangyan@anl.gov (F. Yan) 
26 Current emission inventories provide information about the mass emissions of different chemical

27 species from different emitting sources without information concerning the size distribution of

28 primary particulate matter (PM). The size distribution information, however, is an important

29 input into chemical transport models that determine the fate of PM and its impacts on climate

30 and public health. At present, models usually make rather rudimentary assumptions about the

31 size distribution of primary PM emissions in their model inputs. In this study, we develop a

32 global and regional, size-resolved, mass emission inventory of primary PM emissions from

33 source-specific combustion components of the residential, industrial, power, and transportation

34 sectors for the year 2010. Uncertainties in the emission profiles are also provided. The global

35 size-resolved PM emissions show a distribution with a single peak and the majority of the mass

36 of particles in size ranges smaller than $1 \mu \mathrm{m}$. The PM size distributions for different sectors and

37 world regions vary considerably, due to the different combustion characteristics. Typically, the

38 sizes of particles decrease in the order: power sector > industrial sector > residential sector >

39 transportation sector. Three emission scenarios are applied to the baseline distributions to study

40 the likely changes in size distribution of emissions as clean technologies are implemented.

\section{HIGHLIGHTS}

42 - Mass-based size distribution of emissions of energy-related combustion sources.

43 - Method to estimate the size distribution of components of the combustion sector.

44 - Global $\mathrm{PM}_{10}$ emissions showing single-mode size distribution with peak around $700 \mathrm{~nm}$.

45 - Discussion of uncertainties in global size distribution emission estimation.

46 - Investigation of mass size distribution changes with emission reduction scenarios.

47 Keywords:

48 Mass size distribution; PM emissions; Combustion sources; Global size-resolved emission 49 inventory 


\section{Introduction}

51 Knowledge of the size distribution of aerosols is essential to understanding climate and 52 human health effects. Aerosol optical properties depend strongly on the size distribution

53 (Haywood and Boucher, 2000; Yu et al., 2006); and sub-micrometer aerosols, which have longer 54 atmospheric lifetimes, scatter more light per unit mass (Seinfeld and Pandis, 2006). Smaller 55 carbonaceous aerosols lead to larger, more negative, direct and indirect aerosol forcing (Bauer et 56 al., 2010). The number of cloud condensation nuclei (CCN) per mass of aerosol depends on the 57 chemical composition of aerosols as a function of size (Anttila et al., 2012; Feingold, 2003;

58 McFiggans et al., 2006). In addition, it is well known that the size distribution of particulate matter (PM) determines the potential for human health effects; small particles can readily

60 penetrate into the deep lung and initiate cardiopulmonary disease (Delfino et al., 2005; Pope and 61 Dockery, 2006). Therefore, it is critical to know the size distribution of PM in the atmosphere,

62 which is dependent both on the size distribution of primary PM and of secondary PM formed in 63 the atmosphere.

Most current climate and chemical transport models have the ability to represent the temporal and spatial variability of the aerosol particle mass distribution but must assume a size distribution for the primary PM emissions in order to calculate radiative effects (Bauer et al., 2010) and transport. Most widely-used PM emission inventories (Bond et al., 2004; Cooke et al., 2002, 1999; Reff et al., 2009; Zhang et al., 2007) have very little size resolution and typically provide only mass emission information. Emission inventories for the U.S. (e.g., the National Emission Inventory (NEI)) and for Europe (e.g., European Monitoring and Evaluation Programme (EMEP)), as well as a few other countries, such as China (e.g., Zhang et al. 2007), provide some size information, but none of them provide continuous size distributions. They contain only very broad size bins such as total suspended particles (TSP), $\mathrm{PM}_{10}$, and $\mathrm{PM}_{2.5}$. Thus, modelers have to

74 choose what sizes to assign for emission fluxes most of the time. The assumed size distributions 75 may introduce a large amount of uncertainty in prediction of $\mathrm{CCN}$ concentrations (Pierce and 76 Adams, 2009; Pierce et al., 2007; Reddington et al., 2013; Spracklen et al., 2011) and estimates

77 of climate forcing (Bauer et al., 2010; Spracklen et al., 2011). 
In this study, we develop the first global emission inventory of $\mathrm{PM}_{10}$ with detailed particle size distribution, especially for submicron particles, and thereby advance our understanding of the effects of particle size. We acknowledge that number size distribution is also important and provides different information from mass size distribution. In this study, we provide size-

82 resolved emissions by mass, since it can be applied directly to currently available PM emission 83 inventories (Bond et al., 2004; Streets et al., 2004; Yan et al., 2014b, 2011; GAINS, 2014)

84 without any modification to their calculation methodologies. We tabulate size distribution 85 profiles from the literature that contain measured size distributions of particle emissions from each source category. Section 2 introduces the methodology used to parameterize the size

87 distributions. Section 3 discusses the size distributions by region, energy sector, and designed 88 scenarios. Conclusions and future work are summarized in Section 4.

\section{Methodology and Datasets}

The size-resolved mass emission inventory in this work is built upon previous work (Bond et al., 2004) that involved coarse or no size resolution. In that work, a technology-based model was constructed to estimate present-day global emissions of black and organic carbon particles. This model determines emissions by apportioning fuel use among different emitting technologies.

94 Such an approach has also been used for historical and future emissions estimates (Bond et al., 2007; Streets et al., 2004; Yan et al., 2014b, 2011). The technology-based model allows us to discriminate size distributions among sources with different technologies, as well as to keep track of their impacts. In this work, we use updated combinations of fuels, combustion technologies, and emission control technologies based on Bond et al. (2004) and apply appropriate size distributions for each combination.

Fig. 1 shows the framework for building a size-resolved emission inventory. First, this work enhances existing compilations through literature review and update. Particle size distributions by sector, fuel, and technology are collected from the literature, as detailed in the Supporting

103 Information (SI). Second, these distributions are parameterized by unimodal or multimodal 104 lognormal distributions, depending on the sample size of each distribution and the availability of 105 data, and presented as mass median diameters (MMD), geometric standard deviation (GSD), and 106 mass mixing ratio or weight (w) within each mode, if the distribution has more than one mode, 
107 as shown in Section 2.2. The modeled size distributions do not reproduce the measurements

108 exactly, so there is uncertainty in the derived parameters, as described in Section 2.3. Third,

109 these size distributions from different data sources are merged. There are insufficient data

110 available to use region-specific measurements. We choose to combine data from all regions to

111 generate a more robust representation of the distribution for a particular technology. When more

112 than one distribution for a single technology is included, these distributions are treated equally

113 and the average of the distributions is used. Finally, the estimated size distributions of each

114 technology are combined with the corresponding mass-based particle emission factors and a fuel

115 consumption activity database to develop a size-resolved emission inventory. The resulting

116 emission inventory gives a continuous mass distribution by particle size. The distribution of total

$117 \mathrm{PM}_{10}$ emissions $(E m)$ along the logarithm of particle diameter $\left(\ln D_{p}\right)$ for each sector $k$ in a

118 specific year $i$ is given by:

119

$E m_{i, k}\left(\ln D_{p}\right)=\sum_{j} \sum_{l} \sum_{m} F C_{i, j, k, l, m} E F_{k, l, m} g_{k, l, m}\left(\ln D_{p}\right)$

120 where $i, j, k, l$, and $m$ represent year, region, sector, fuel, and fuel/technology combination,

121 respectively. $E m$ is emission, $F C$ is fuel consumption (kg/year), $E F$ is emission factor (g/kg fuel)

122 specific to a fuel/technology combination (including the effect of any control devices), $D_{p}$ is

123 particle diameter, and $g(\ln D p)$ is the particle size distribution of $\mathrm{PM}_{10}$ in the form of a single- or

124 multi- lognormal distribution (see Section 2.2).

125 Mass fractions within certain size bins (e.g., $\mathrm{PM}_{1}, \mathrm{PM}_{1-2.5}$, and $\mathrm{PM}_{2.5-10}$ ) can also be

126 computed by the integrals of the distribution. Using $\mathrm{PM}_{1-2.5}$ as an example, it can be estimated by:

$M F_{a, b}=\frac{\int_{\ln a}^{\ln b} E m\left(\ln D_{p}\right)}{\int_{-\infty}^{\ln (10)} E m\left(\ln D_{p}\right)}$

128 where $M F$ is the mass fraction, $a=1 \mu \mathrm{m}$, and $b=2.5 \mu \mathrm{m}$.

\subsection{Database of size distributions}

We separate particle-size distributions based on different combinations of fuel, sector, and technology. The reasons are: (1) the particle-size distributions are diverse for different 
132 combustion and emission control technologies; (2) we can keep track of the individual

133 contributions of particle-size distribution from each technology and thus have a better picture of

134 the effects of emission control strategies; and (3) the grouping of technologies is consistent with

135 our previous emission inventory, which enables us to apply the existing database of emission

136 factors and corresponding activity levels. The size distribution information for all combustion

137 sources used in this study is provided in the SI, where we discuss the development of the size-

138 distribution information database. The discussion in SI also includes the review of size

139 distribution data for important sources (large $\mathrm{PM}_{10}$ contributors) in the residential, industrial,

140 power, and transportation sectors. It should be noted that size distribution information is not

141 available for a few combustion sources; in such cases, we selected the size distribution of similar

142 sources (similar combustion or fuel types, etc.) to represent those sources for which data are not 143 available.

\subsection{Parameterization of size distribution}

145 A lognormal distribution often provides a good fit to the particle-size distribution and is 146 commonly used in atmospheric studies (Aitchison and Brown, 1957; Friedlander, 1977; Whitby, 147 1974). Extensive discussions of the use of lognormal distributions for representing aerosols can 148 be found in the literature (e.g., Hinds (1998) and Seinfeld and Pandis (2006)). The particle-size 149 distribution for a single mode, expressed as the mass of particles $(M)$ per logarithmic size $\left(\ln D_{p}\right)$ 150 interval, can be formulated as:

$$
\frac{d M}{d \ln D_{p}}=\frac{M_{t}}{\sqrt{2 \pi} \ln \sigma_{g}} \exp \left[-\frac{\left(\ln D_{p}-\ln \bar{D}_{p g}\right)^{2}}{2 \ln ^{2} \sigma_{g}}\right]
$$

152 where $D_{p}$ is the particle diameter, $\bar{D}_{p g}$ is the mass median diameter (MMD), $\sigma_{g}$ is the geometric 153 standard deviation (GSD) of the distribution, and $M_{t}$ is the total aerosol mass concentration. This 154 study provides MMD information because it is then easier to represent the combination of size 155 distribution and mass-based emission inventory. Count median diameter (CMD) is usually used 156 by climate modelers and it can be converted using the Hatch-Choate relationship:

$157 \quad M M D=C M D \exp \left(3 \ln ^{2} \mathrm{GSD}\right)$ 

processes that occur prior to emission, the particle-size distribution may be characterized by more than one mode. For example, the mass distribution is usually dominated by two modes: the

161 accumulation mode (from $\sim 0.1$ to $\sim 2 \mu \mathrm{m}$ ) and the coarse mode (from $\sim 2$ to $\sim 50 \mu \mathrm{m}$ ) (Seinfeld

162 and Pandis, 2006). Particle-size distribution features with multiple modes can be described as the 163 sum of lognormal distributions:

$164 \frac{d M}{d \ln D_{p}}=M_{1} f_{1}\left(\ln D_{p}\right)+M_{2} f_{2}\left(\ln D_{p}\right)+\ldots+M_{k} f_{k}\left(\ln D_{p}\right)$

165 where $k$ is the number of components in the mixture distribution, with $f_{k}\left(\ln D_{p}\right)$ being the 166 lognormal distribution for mode $k$ :

$f_{k}\left(\ln D_{p}\right)=\frac{1}{\sqrt{2 \pi} \ln \sigma_{g k}} \exp \left[-\frac{\left(\ln D_{p}-\ln \bar{D}_{p g k}\right)^{2}}{2 \ln ^{2} \sigma_{g k}}\right]$

Equation (6) can be normalized by the total mass concentration $M_{t}=\sum_{i=1}^{k} M_{i}$, so that the

169 fitted curve of particle-size distribution is independent of the measured total mass, and the area 170 under the curve ( $\ln D_{p}$ from $-\infty$ to $+\infty$, or $D_{p}$ from 0 to $+\infty$ ) is equal to 1 . The normalized particle 171 size distribution by mass can be expressed as:

$g\left(\ln D_{p}\right)=w_{1} f_{1}\left(\ln D_{p}\right)+w_{2} f_{2}\left(\ln D_{p}\right)+\ldots+w_{k} f_{k}\left(\ln D_{p}\right)$

173 where $w_{k}=\frac{M_{k}}{\sum_{i=1}^{k} M_{i}}$ is the mass fraction of the $f_{k}$ in the mixture distribution and termed "mixing

174 weight" in this study.

175 Equation (7) is applicable to TSP, because this distribution is assumed to cover all particle 176 sizes. Equation (8) is needed if an emission factor for a specific size of particle is applied. In this 177 study, emissions of $\mathrm{PM}_{10}$ are used, and the adjustment is expressed as: 


$$
\text { where } \alpha \text { is the adjusted ratio that can be computed as } \alpha=\frac{1}{\int_{-\infty}^{\ln D_{p t}} g\left(\ln D_{p}\right) d \ln D_{p}} \text { with } D_{p t} \text { being }
$$

the target particle size and $D_{p t}=10 \mu \mathrm{m}$ in this study.

In this work, we apply the method of nonlinear least-squares when fitting the measured data from reference materials. To obtain the coefficient estimates, the least-squares method minimizes

183 the summed square of residuals. We use the curve-fitting toolbox from Matlab to fit published 184 data on mass size distribution and estimate the mixing weight for each mode (w), MMD $\left(\bar{D}_{p g}\right)$, and GSD $\left(\sigma_{g}\right)$ with the nonlinear model described in Equations (6) and (7).

\subsection{Uncertainties in size distribution}

Uncertainties in fuel consumption activity and emission factors of PM are widely acknowledged and quantified in several studies (Lu et al., 2011; Yan et al., 2014a; Zhao et al., 2011), but few attempts have been made to examine uncertainties in the particle size distribution.

190 In this work, we use nonlinear regression to parameterize size distribution, as described in 191 Section 2.2. Uncertainties are introduced by fitting curves, which do not reproduce measured

192 values exactly. In this work, we only consider the uncertainty due to fittings of lognormal 193 distributions. Uncertainties caused by different measurements for the same technology are not 194 included. The non-simultaneous prediction bounds for the function at a single predictor value ln $195 D_{p, 0}$ are quantified by:

$P\left(\ln D_{p, 0}\right)=g\left(\ln D_{p, 0}\right) \pm t_{\alpha / 2, n-m} \sqrt{\ln D_{p, 0} S \ln D_{p, 0}^{T}}$

where $t$ depends on the confidence level $(1-\alpha)$ and is computed using the inverse of the Student's

198 t-test cumulative distribution function, $n$ is the number of observations, $m$ is the number of

199 coefficients, and $S$ is the covariance matrix of the coefficient estimates.

200 Fig. 2 shows two examples of $\mathrm{PM}_{10}$ size distribution by mass: one is from a power plant 201 boiler with ESP (Zhao et al., 2010), and the other is from the open burning of wheat straw (Li et 
al., 2007). The size distributions of $\mathrm{PM}_{10}$ given in both references were measured by an electrical

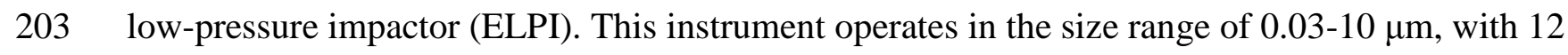

204 stages. Fig. 2 presents the parameterization of the size distribution, as well as the 95\%

205 confidence interval (CI) of the predicted curve. The size distribution of $\mathrm{PM}_{10}$ emissions from the

206 boiler fits a curve with two lognormal distributions and MMDs of $0.2 \mu \mathrm{m}$ and $3.8 \mu \mathrm{m}$, while the

207 one from open burning of crop residue fits a single lognormal distribution with MMD of $0.3 \mu \mathrm{m}$.

208 The width of the $95 \%$ CI indicates a larger uncertainty for the smaller particles if the simulated

209 curve is used to predict size distributions for $\mathrm{PM}_{10}$ emissions from boilers with ESP. This kind of

210 analysis is performed for all fuel and technology combinations.

211 We then use a Monte Carlo approach to determine the uncertainties in the size distribution of 212 total emissions by sector and region. The procedure is to generate a set of random values of size

213 distributions at $P\left(\ln D_{p, 0}\right)$ for specific particle diameter $\left(\ln D_{p, 0}\right)$ of each fuel/technology

214 combination. We assume normal distributions for the predicted values $P\left(\ln D_{p, 0}\right)$, and standard

215 deviation is estimated by $\sqrt{\ln D_{p, 0} S \ln {D_{p, 0}}^{T}}$ which depends on the particle size.

\section{$2.4 P M_{10}$ emission inventory}

217 The $\mathrm{PM}_{10}$ emission inventory used in this study is based on previous studies (Bond et al., 2007, 218 2004; Lu et al., 2011; Streets et al., 2009, 2006; Yan et al., 2014b, 2011). Emission rates change

219 widely due to different types of processes and control technologies, and therefore a technology-

220 based methodology is necessary for estimating emissions from all anthropogenic combustion

221 sources. Emission sources are categorized into four major sectors, including residential,

222 industrial, power, and transportation, and more than 90 combinations of sector, fuel, and

223 technology. Energy and fossil-fuel consumption data in 2010 for different combinations of sector,

224 fuel, and technology are derived from International Energy Agency statistics (IEA, 2012a,

225 2012b). The fuel consumption activities are separated and aggregated based on the emission

226 characteristics of each combustion process to fit the source types in our emission inventory (see

227 Bond et al. (2004) for details). In particularly, we separate fuel consumption for on-road vehicles 228 and agricultural tractors by emission standards (see Yan et al. (2014b) for details). We apply TSP 229 emission factors from Bond et al. $(2004,2007)$ combined with the mass fractions of $\mathrm{PM}_{10}$ to TSP 230 from the GAINS model (GAINS, 2014) to estimate $\mathrm{PM}_{10}$ emission factors, except for on-road 
231 vehicles and agricultural tractors which use primary TSP emission factors from Yan et al. (2014b)

232 and the mass fraction of $\mathrm{PM}_{10}$ to TSP from Norbeck et al.(1998). Finally, fuel consumption

233 activities for each set of sector, fuel, and technology and their corresponding emission factors are

234 combined to estimate total emissions, as shown in Table 1.

\section{Results and Discussion}

236 Regional size-resolved emissions for each sector are presented in Section 3.1 where we 237 discuss the primary sources that dominate the emission size distribution by mass. Then, we 238 compute emissions across all source types and present the global $\mathrm{PM}_{10}$ emission size

239 distributions for all sectors in Section 3.2. Finally, in Section 3.3, we discuss the potential shifts 240 in PM size that would be caused by the implementation of certain improved emission control 241 technologies.

242

243

244

\subsection{Regional size-resolved $P M_{10}$ emissions}

In this section we discuss the drivers of the size distribution patterns and uncertainties in each sector based on regional emissions. Sources that dominate mass emissions also dominate the size distribution, so that regions with similar emission contributions from the various sources also share similar size distributions. Representative regions are chosen for illustration and discussion. The selection of these regions is based on size distribution, such as number and position of peaks, and large mass contribution to global emissions and uncertainty.

\subsubsection{Residential sector}

Because solid fuels produce most of the $\mathrm{PM}_{10}$ in the residential sector, the size distribution of $\mathrm{PM}_{10}$ is dominated by the combustion of solid fuels. We present size distributions for OECD Europe, India, and China to represent characteristic distribution patterns of major emission sources in the residential sector where different technologies dominate, as shown in Figure 3. In OECD Europe, $\mathrm{PM}_{10}$ emissions typically show a bimodal distribution having peaks at around $100 \mathrm{~nm}$ and $400 \mathrm{~nm}$. These two modes are primarily contributed by fireplaces and heating stoves. Bimodal distributions are also found in emissions from India. Emissions from agricultural waste, dung, and biomass cookstoves are the major sources of $\mathrm{PM}_{10}$ emissions in the range of 50-2000 $\mathrm{nm}$ with a peak at $700 \mathrm{~nm}$. The other peak at $4000-5000 \mathrm{~nm}$ is due to PM emissions from 
traditional cookstoves burning hard coal. Uncertainties around the peak in OECD Europe and

260 India are due to uncertainties in the estimated size distribution for heating stoves. In China, $\mathrm{PM}_{10}$

261 emissions show a trimodal distribution. The peak at $300 \mathrm{~nm}$ is from combustion of hard coal in

262 open fires. The other two peaks at $600 \mathrm{~nm}$ and $5000 \mathrm{~nm}$ are caused by combustion of fuelwood,

263 agricultural waste, and hard coal in traditional stoves. Large uncertainties in the estimated size

264 distribution of particles smaller than $1000 \mathrm{~nm}$ are primarily associated with agricultural waste

265 burning.

\subsubsection{Industrial sector}

Major emission sources in this sector are coal-fired kilns. Because emissions from industrial sources are dominated by coal combustion, the overall size distributions in this sector are similar among regions. Size distributions of emissions from the industrial sector in China and Southeast Asia are shown in Fig. 4. A single-peak distribution is the predominant size distribution for $\mathrm{PM}_{10}$,

271 while another peak, dominated by coking-coal combustion, is present beyond the $\mathrm{PM}_{10}$ size

272 range. In both regions, the primary emission source is cement kilns, which contribute the peak at

$273600 \mathrm{~nm}$. In China, the coking-coal process primarily determines the shape of the distribution

274 above $3000 \mathrm{~nm}$. In Southeast Asia, other than cement kilns, another major source is traditional

275 biofuel combustion, which gives rise to the peak at $600 \mathrm{~nm}$. There is no peak beyond $\mathrm{PM}_{10}$ in this 276 region since coking-coal emissions are not significant. For both regions, emissions from cement

277 kilns contribute most to the uncertainty of the size distribution. Smaller uncertainties are found in

278 China for particles larger than $3000 \mathrm{~nm}$ and in Southeast Asia for particles smaller than 100

$279 \mathrm{~nm}$ - because of lower uncertainties contributed by the coking-coal process and biofuel 280 combustion, respectively.

\section{$281 \quad 3.1 .3 \quad$ Power plant sector}

282 The primary emission source in the power sector is coal combustion. Some other fuels, such 283 as natural gas and heavy oil, also contribute a small share to regional emissions. In this sector, 284 we use the size distribution of emissions from OECD Europe and Eastern Europe to show the 285 contribution from major emission sources, as presented in Fig. 5. In both regions, $\mathrm{PM}_{10}$ 286 emissions generally show a bimodal distribution but with different details. In OECD Europe, 287 emissions peak at $200 \mathrm{~nm}$ and $2000 \mathrm{~nm}$. The major contributors of the two peaks in this region 
are combustion of biofuels, pulverized-coal combustion with ESP, and waste combustion, which

289 have bimodal distributions with MMDs at 160-300 $\mathrm{nm}$ and 2000-3000 $\mathrm{nm}$. The major

290 uncertainty of the size distribution in this sector is from pulverized-coal combustion with

291 electrostatic precipitators. In Eastern Europe, major emissions and uncertainty sources are from

292 pulverized-coal combustion with cyclone collectors and ESP.

\section{$293 \quad 3.1 .4 \quad$ Transportation sector}

294 The size distribution of $\mathrm{PM}_{10}$ in the transportation sector is dominated by the combustion of 295 diesel fuel. On-road vehicles, non-road engines, and international shipping are major PM 296 emission sources in 2010. The size distributions for this sector are presented in Fig. 6. In the 297 three regions selected - the U.S., Southern Africa, and Southeast Asia-multi-mode mass 298 distributions having a major peak between $100 \mathrm{~nm}$ and $200 \mathrm{~nm}$ are typical characteristics of the 299 transportation sector. This peak is contributed primarily by two-stroke engines, heavy-duty diesel 300 vehicles, and heavy-fuel-oil combustion for international shipping. In the U.S., the peaks at 20 $301 \mathrm{~nm}$ and $5000 \mathrm{~nm}$ are due to clean diesel vehicles meeting post-1998 emission standards and 302 international shipping, respectively. Heavy-duty diesel vehicles without emission standards and 303 two-stroke engines with poor maintenance are the major emission sources in Southern Africa, 304 showing peaks at $50 \mathrm{~nm}$ and $150 \mathrm{~nm}$. In Southeast Asia, the emission peaks at $20 \mathrm{~nm}, 150 \mathrm{~nm}$, $3051000 \mathrm{~nm}$, and $5000 \mathrm{~nm}$ are primarily contributed by heavy-duty diesel vehicles without emission 306 standards, superemitters, international shipping, and two-stroke engines. The large uncertainties 307 for size distribution estimation in this sector are contributed by international shipping and 308 vehicles without emission standards.

\section{$309 \quad 3.2 \quad$ Global size-resolved PM emissions}

310 Fig. 7 shows global size-resolved emissions from the four sectors: residential, industrial, 311 power, and transportation. These four sectors exhibit dramatically different distributions.

312 Residential emissions show a bimodal distribution with peaks at $600 \mathrm{~nm}$ and $5000 \mathrm{~nm}$. These 313 peaks are determined by the size distributions of emissions from solid-fuel combustion. In the 314 industrial sector, $\mathrm{PM}_{10}$ emissions show a peak at around $600 \mathrm{~nm}$ contributed primarily by 315 emissions from kilns in the developing world, i.e., cement, lime, and brick kilns. Emissions from 316 the combustion of solid fuels and waste in the power sector dominate the size distribution and 
317 lead to two peaks at $200 \mathrm{~nm}$ and $2000 \mathrm{~nm}$. In the transportation sector, one peak is found

318 between 100-200 nm governed by emissions from vehicles and international shipping, with three

319 other peaks at $20 \mathrm{~nm}, 1000 \mathrm{~nm}$, and $6000 \mathrm{~nm} . \mathrm{PM}_{10}$ emissions from the residential and

320 transportation sectors tend to be of smaller size than those from the industrial and power sectors,

321 since particles resulting from coal combustion, which is a major source in the industrial and

322 power sectors, tend to be larger than those from biomass combustion in the residential sector and

323 gasoline and diesel combustion in the transportation sector. Global emissions and regional

324 contributions are summarized in Table 2 . In the residential sector, we find that $86 \%$ of total $\mathrm{PM}_{10}$

325 by mass is $\mathrm{PM}_{1}$, while $\mathrm{PM}_{2.5-10}$ contributes only $4 \%$ of total $\mathrm{PM}_{10}$ emissions. For transportation,

$32692 \%$ of $\mathrm{PM}_{10}$ is smaller than $1 \mu \mathrm{m}$ and $5 \%$ of total emissions fall between $\mathrm{PM}_{10}$ and $\mathrm{PM}_{2.5}$. By

327 contrast, in the industrial and power sectors, $54 \%$ and $42 \%$ of total emissions are contributed by

$328 \mathrm{PM}_{1}$, respectively. $\mathrm{PM}_{2.5-10}$ contributes $28 \%$ and $33 \%$, and $\mathrm{PM}_{1-2.5}$ contributes $18 \%$ and $26 \%$,

329 respectively. Large uncertainties are found in the particle size range between $100 \mathrm{~nm}$ and 1000

$330 \mathrm{~nm}$ for the residential, industrial, and power sectors, while small uncertainties are found in this

331 particle size range for the transportation sector.

332 The global size-resolved emission distribution across all regions is presented in Fig. 8. This

333 global average shows a single-mode lognormal distribution with peaks at 600-700 nm, reflecting

334 the fact that global size-resolved $\mathrm{PM}_{10}$ emissions are dominated by the industrial and residential

335 sectors, as shown in Fig. 8 (a). $\mathrm{PM}_{2.5}$ and $\mathrm{PM}_{1}$ contribute $82 \%$ and $67 \%$, respectively, to total

336 global $\mathrm{PM}_{10}$ emissions. The majority of $\mathrm{PM}_{10}$ emissions are from combustion sources yielding

337 particles smaller than $1 \mu \mathrm{m}$. Fig. 8 (b) shows the global size distribution by world region. Global

338 particulate emissions are dominated by emissions in China, which contribute 36\%, 33\%, and 31\%

339 of global $\mathrm{PM}_{10}, \mathrm{PM}_{2.5}$, and $\mathrm{PM}_{1}$, respectively. The ratios of regional to global $\mathrm{PM}$ emissions do

340 not change much for $\mathrm{PM}_{10}, \mathrm{PM}_{2.5}$, and $\mathrm{PM}_{1}$ in each region, suggesting that all regions contribute

341 roughly the same fractions of $\mathrm{PM}_{10}$ emissions in the different size ranges. Uncertainties in size-

342 resolved emissions are larger in the particle size range between $100 \mathrm{~nm}$ and $5000 \mathrm{~nm}$ than in

343 other size ranges. 
345 In this section we examine the potential effects of adopting a higher level of PM emission control on the global $\mathrm{PM}_{10}$ size distribution. In doing this, we focus more on changes in the size

347 distribution pattern than in the overall magnitude of $\mathrm{PM}_{10}$ emissions. We also do not pass 348 judgment on the feasibility of these scenarios - they serve purely to illustrate the shifting size 349 patterns. Three scenarios focusing on three major global $\mathrm{PM}_{10}$ sources are investigated:

(1) Clean household-fuel combustion scenario (S1). In this scenario, no solid fuel is used for cooking and heating in the home - it is substituted by LPG and natural gas, respectively.

(2) Controlled cement kiln scenario (S2). In this scenario, baghouses are used to control emissions from all cement kilns, which are the major emission contributors in the industrial sector; the size-specific emission reduction profile assumed for this technology is $32 \%$ for $\mathrm{PM}_{10}$ and $40 \%$ for $\mathrm{PM}_{2.5}$ (Lei et al., 2011).

(3) Clean vehicle scenario (S3). In this scenario, it is assumed that all on-road vehicles meet Euro 6 emission standards and that no superemitters remain in the fleet.

The $\mathrm{PM}_{10}$ regional emissions under the three scenarios are given in Table 1. Fig. 9 shows the global size distributions of $\mathrm{PM}_{10}$ in the baseline and the three emission reduction scenarios. In scenario S1, as shown in Fig. 9 (a), the size distribution shifts to a smaller size range with peaks at $20 \mathrm{~nm}$ and $200 \mathrm{~nm}$. Compared with the baseline distribution, higher emissions of smaller particles are caused by increasing amounts of LPG and natural gas combustion. In the range between $1 \mu \mathrm{m}$ and $10 \mu \mathrm{m}$, the mass emissions shift from having peaks at $600 \mathrm{~nm}$ and $5000 \mathrm{~nm}$ in the baseline to $200 \mathrm{~nm}$ in $\mathrm{S} 1$, with a total mass reduction of $99 \%$.

In scenario S2, shown in Fig. 9 (b), there is no significant change in the shape of the size distribution, but PM emissions in size ranges smaller than $3000 \mathrm{~nm}$ and larger than $100 \mathrm{~nm}$ are reduced significantly, due to the performance of the baghouses. Overall, $\mathrm{PM}_{10}$ emissions from the industrial sector are reduced by $15 \%$ from the baseline scenario. Emissions of $\mathrm{PM}_{2.5-10}$ are reduced by only $1 \%$ from the baseline, because the contribution of cement kilns to total emissions is much less than the contribution of the coking-coal process for PM larger than 3000 nm. $\mathrm{PM}_{1-2.5}$ and $\mathrm{PM}_{1}$ are reduced by $19-21 \%$, with a significant reduction for PM larger than 100 $\mathrm{nm}$, where emissions from cement kilns dominate the size distribution. 
In scenario S3, forcing all vehicles to follow Euro 6 emission standards significantly reduces 374 emissions of PM with sizes smaller than $2.5 \mu \mathrm{m}$. There is no change in the shape of the $\mathrm{PM}_{10}$ 375 size distribution from the baseline, except that a small peak at $50 \mathrm{~nm}$ emerges that is associated 376 with the Euro 6 vehicles, as shown in Fig. 9 (c). The overall emission reduction in the 377 transportation sector is $39 \%$ with less than $1 \%$ change in $\mathrm{PM}_{2.5-10}$ from baseline. Reductions of $37 \%$ and $41 \%$ are achieved in $\mathrm{PM}_{1-2.5}$ and $\mathrm{PM}_{1}$, respectively.

If all of the measures described above were to be applied at the same time, total $\mathrm{PM}_{10}$ emissions would be reduced by $43 \%$ from the baseline. Although emissions of particles smaller than $100 \mathrm{~nm}$ increase, mainly due to the increase of LPG and natural gas emissions, mass emissions are less in all $\mathrm{PM}$ size ranges. $\mathrm{PM}_{2.5-10}, \mathrm{PM}_{1-2.5}$, and $\mathrm{PM}_{1}$ are reduced by $8 \%, 37 \%$, and $54 \%$, respectively. Because emissions are reduced by a large amount in the residential sector, the global size distribution exhibits a different shape from the baseline. Four peaks are now observed in the global size distribution, contributed by the residential sector (at $20 \mathrm{~nm}$ and $2000 \mathrm{~nm}$ ), the industrial sector (at $600 \mathrm{~nm}$ ), and the transportation sector (at $20 \mathrm{~nm}$ and $200 \mathrm{~nm}$ ).

\section{Conclusions}

In this work, we develop the first global and regional size-resolved $\mathrm{PM}_{10}$ mass emission inventory that covers all energy-related combustion sources. We collate particle size distribution information for all important types of combustion sources from the literature. Continuous size

391 distributions across the full range of PM sizes less than $\mathrm{PM}_{10}$ are assembled for all combustion 392 types, and $\mathrm{PM}$ emissions in three size ranges $\left(\mathrm{PM}_{10}, \mathrm{PM}_{2.5}\right.$, and $\left.\mathrm{PM}_{1}\right)$ and two size bins $\left(\mathrm{PM}_{2.5-10}\right.$ 393 and $\mathrm{PM}_{2.5-1}$ ) are summarized for the residential, industrial, power, and transportation sectors. The uncertainty associated with each size-resolved emission profile is also calculated. Global PM $_{10}$ emissions from combustion sources are dominated by particle sizes smaller than $1 \mu \mathrm{m}$. $\mathrm{PM}_{10}$ emissions in the four sectors show different particle size distributions due to the different characteristics of the fuels and technologies used in each sector. In the residential and transportation sectors, $80-90 \%$ of emissions are smaller than $1 \mu \mathrm{m}$, with less than $5 \%$ of emissions from $\mathrm{PM}_{2.5-10}$. In the industrial and power sectors, only 40-50\% of emissions are in the

$400 \mathrm{PM}_{1}$ size range, while around $20-25 \%$ of emissions are in both $\mathrm{PM}_{2.5-10}$ and $\mathrm{PM}_{1-2.5}$. Three 401 emission scenarios were studied to represent tighter emission limits in three sectors: switching 
from solid fuels to LPG and natural gas in the residential sector, installing baghouses to control

403 emissions from cement kilns, and using Euro 6 emission limits for all in-use vehicles. Two of

404 these scenarios show similar mass size distribution emission patterns as the baseline, while, in

405 the residential sector, particle mass sizes are shifted to smaller size ranges. Despite the quantified

406 uncertainties in this size-resolved $\mathrm{PM}_{10}$ emission database, its use in global and regional

407 chemistry and climate models should be a great improvement over the rudimentary

408 representations in current usage. This will, in turn, lead to improved quantification of human

409 health and climate impacts. An evaluation of this size-resolved PM emission inventory through

410 modeling and comparisons with observations is planned for the future. Additional measurements

411 of size-resolved $\mathrm{PM}_{10}$ emissions from key combustion sources where data are presently limited

412 would enable us to improve the distributions presented here.

\section{Acknowledgments}

414 This work was supported by the U.S. Environmental Protection Agency under grant RD415 83503401. This paper has not been subject to EPA's required peer and policy review, and 416 therefore does not necessarily reflect the views of the Agency. No official endorsement should 417 be inferred. Argonne National Laboratory is operated by UChicago Argonne, LLC, under 418 Contract No. DE-AC02-06CH11357 with the U.S. Department of Energy.

\section{References}

Aitchison, J., Brown, J.A.C., 1957. The lognormal distribution function. Cambridge University Press, Cambridge, UK.

Anttila, T., Brus, D., Jaatinen, A., Hyvärinen, A.P., Kivekäs, N., Romakkaniemi, S., Komppula, M., Lihavainen, H., 2012. Relationships between particles, cloud condensation nuclei and cloud droplet activation during the third Pallas Cloud Experiment. Atmospheric Chemistry and Physics 12, 11435-11450.

Bauer, S.E., Menon, S., Koch, D., Bond, T.C., Tsigaridis, K., 2010. A global modeling study on carbonaceous aerosol microphysical characteristics and radiative effects. Atmospheric Chemistry and Physics 10, 7439-7456.

Bond, T.C., Bhardwaj, E., Dong, R., Jogani, R., Jung, S., Roden, C., Streets, D.G., Trautmann, N.M., 2007. Historical emissions of black and organic carbon aerosol from energy-related combustion, 1850-2000. Global Biogeochemical Cycles 21, GB2018. 
Bond, T.C., Streets, D.G., Yarber, K.F., Nelson, S.M., Woo, J.H., Klimont, Z., 2004. A technology-based global inventory of black and organic carbon emissions from combustion. Journal of Geophysical Research 109, D14203.

Cooke, W.F., Liousse, C., Cachier, H., Feichter, J., 1999. Construction of a 1 x 1 fossil fuel emission data set for carbonaceous aerosol and implementation radiative impact in the ECHAM4 model. Journal of Geophysical Research 104, D18.

Cooke, W.F., Ramaswamy, V., Kasibhatla, P., 2002. A general circulation model study of the global carbonaceous aerosol distribution. Journal of Geophysical Research 107, D16.

Delfino, R.J., Sioutas, C., Malik, S., 2005. Potential Role of Ultrafine Particles in Associations between Airborne Particle Mass and Cardiovascular Health. Environmental Health Perspectives 113, 934-946.

Feingold, G., 2003. Modeling of the first indirect effect: Analysis of measurement requirements. Geophysical Research Letters 30, 19.

Friedlander, S.K., 1977. Smoke, dust and haze, fundamentals of aerosol behavior. John Wiley and Sons, New York, USA.

GAINS, 2014. Greenhouse Gas - Air Pollution Interactions and Synergies. http://gains.iiasa.ac.at/models/ (accessed in June 2014).

Haywood, J., Boucher, O., 2000. Estimates of the direct and indirect radiative forcing due to tropospheric aerosols: a review. Reviews of Geophysics 38, 513-543.

Hinds, W.C., 1998. Aerosol technology. John Wiley \& Sons, New York.

International Energy Agency (IEA), 2012a. Energy Statistics of Non-OECD Countries CD-ROM Paris, France.

International Energy Agency (IEA), 2012b. Energy Statistics of OECD Countries CD-ROM Paris, France.

Lei, Y., Zhang, Q., Nielsen, C., He, K., 2011. An inventory of primary air pollutants and CO2 emissions from cement production in China, 1990-2020. Atmospheric Environment 45, $147-154$.

Li, X., Duan, L., Wang, S., Duan, J., Guo, X., Yi, H., 2007. Emission characteristics of particulate matter from rural household biofuel combustion in China. Energy and Fuels 21, $845-851$

Lu, Z., Zhang, Q., Streets, D.G., 2011. Sulfur dioxide and primary carbonaceous aerosol emissions in China and India, 1996-2010. Atmospheric Chemistry and Physics 11, 98399864. 
McFiggans, G., Artaxo, P., Baltensperger, U., Coe, H., Facchini, M.C., Feingold, G., Fuzzi, S., Gysel, M., Fisica, D., Paulo, U.D.S., Matao, R., Travessa, R., Paulo, C.E.P.S., 2006. The effect of physical and chemical aerosol properties on warm cloud droplet activation. Atmospheric Chemistry and Physics 6, 2593-2649.

Pierce, J.R., Adams, P.J., 2009. Uncertainty in global CCN concentrations from uncertain aerosol nucleation and primary emission rates. Atmospheric Chemistry and Physics 9, 1339-1356.

Pierce, J.R., Chen, K., Adams, P.J., 2007. Contribution of primary carbonaceous aerosol to cloud condensation nuclei: processes and uncertainties evaluated with a global aerosol microphysics model. Atmospheric Chemistry and Physics 7, 5447-5466.

Pope, C.A., Dockery, D.W., 2006. Health effects of fine particulate air pollution: Lines that connect. Journal of Air and Waste Management Association 56, 709-742.

Reddington, C.L., McMeeking, G., Mann, G.W., Coe, H., Frontoso, M.G., Liu, D., Flynn, M., Spracklen, D. V., Carslaw, K.S., 2013. The mass and number size distributions of black carbon aerosol over Europe. Atmospheric Chemistry and Physics 13, 4917-4939.

Reff, A., Bhave, P. V, Simon, H., Pace, T.G., Pouliot, G.A., Mobley, J.D., Houyoux, M., 2009. Emissions inventory of PM2.5 trace elements across the United States. Environmental Science \& Technology 43, 5790-5796.

Seinfeld, J.H., Pandis, S.N., 2006. Atmospheric chemistry and physics-from air pollution to climate change, 2nd ed. John Wiley \& Sons, Hoboken, New Jersey.

Spracklen, D.V., Carslaw, K.S., Pöschl, U., Rap, A., Forster, P.M., 2011. Global cloud condensation nuclei influenced by carbonaceous combustion aerosol. Atmospheric Chemistry and Physics 11, 9067-9087.

Streets, D.G., Bond, T.C., Lee, T., Jang, C., 2004. On the future of carbonaceous aerosol emissions. Journal of Geophysical Research 109, D24212.

Streets, D.G., Wu, Y., Chin, M., 2006. Two-decadal aerosol trends as a likely explanation of the global dimming/brightening transition. Geophysical Research Letters 33, L15806.

Streets, D.G., Yan, F., Chin, M., Diehl, T., Mahowald, N., Schultz, M., Wild, M., Wu, Y., Yu, C., 2009. Anthropogenic and natural contributions to regional trends in aerosol optical depth, 1980-2006. Journal of Geophysical Research 114, D00D18.

Whitby, K.T., 1974. Modeling of multimodal aerosol distributions, GAF Meeting, October 1974, Bad Soden, Germany.

Yan, F., Winijkul, E., Bond, T.C., Streets, D.G., 2014a. Global emission projections of particulate matter (PM): II. Uncertainty analyses of on-road vehicle exhaust emissions. Atmospheric Environment 87, 189-199. 
Yan, F., Winijkul, E., Jung, S., Bond, T.C., Streets, D.G., 2011. Global emission projections of particulate matter (PM): I. Exhaust emissions from on-road vehicles. Atmospheric Environment 45, 4830-4844.

Yan, F., Winijkul, E., Streets, D.G., Lu, Z., Bond, T.C., Zhang, Y., 2014b. Global emission projections for the transportation sector using dynamic technology modeling. Atmospheric Chemistry and Physics 14, 5709-5733.

Zhang, Q., Streets, D.G., He, K., Klimont, Z., 2007. Major components of China's anthropogenic

Yu, H., Kaufman, Y.J., Chin, M., Feingold, G., Remer, L.A., Anderson, T.L., Balkanski, Y., Bellouin, N., 2006. A review of measurement-based assessments of the aerosol direct radiative effect and forcing. Atmospheric Chemistry and Physics 6, 613-666.

511 Zhao, Y., Nielsen, C.P., Lei, Y., McElroy, M.B., Hao, J., 2011. Quantifying the uncertainties of a 512 bottom-up emission inventory of anthropogenic atmospheric pollutants in China.

513 Atmospheric Chemistry and Physics 11, 2295-2308.

514 Zhao, Y., Wang, S., Nielsen, C.P., Li, X., Hao, J., 2010. Establishment of a database of emission 515 factors for atmospheric pollutants from Chinese coal-fired power plants. Atmospheric Environment 44, 1515-1523. 
PM size distribution from literature

(by sector, fuel and technology)

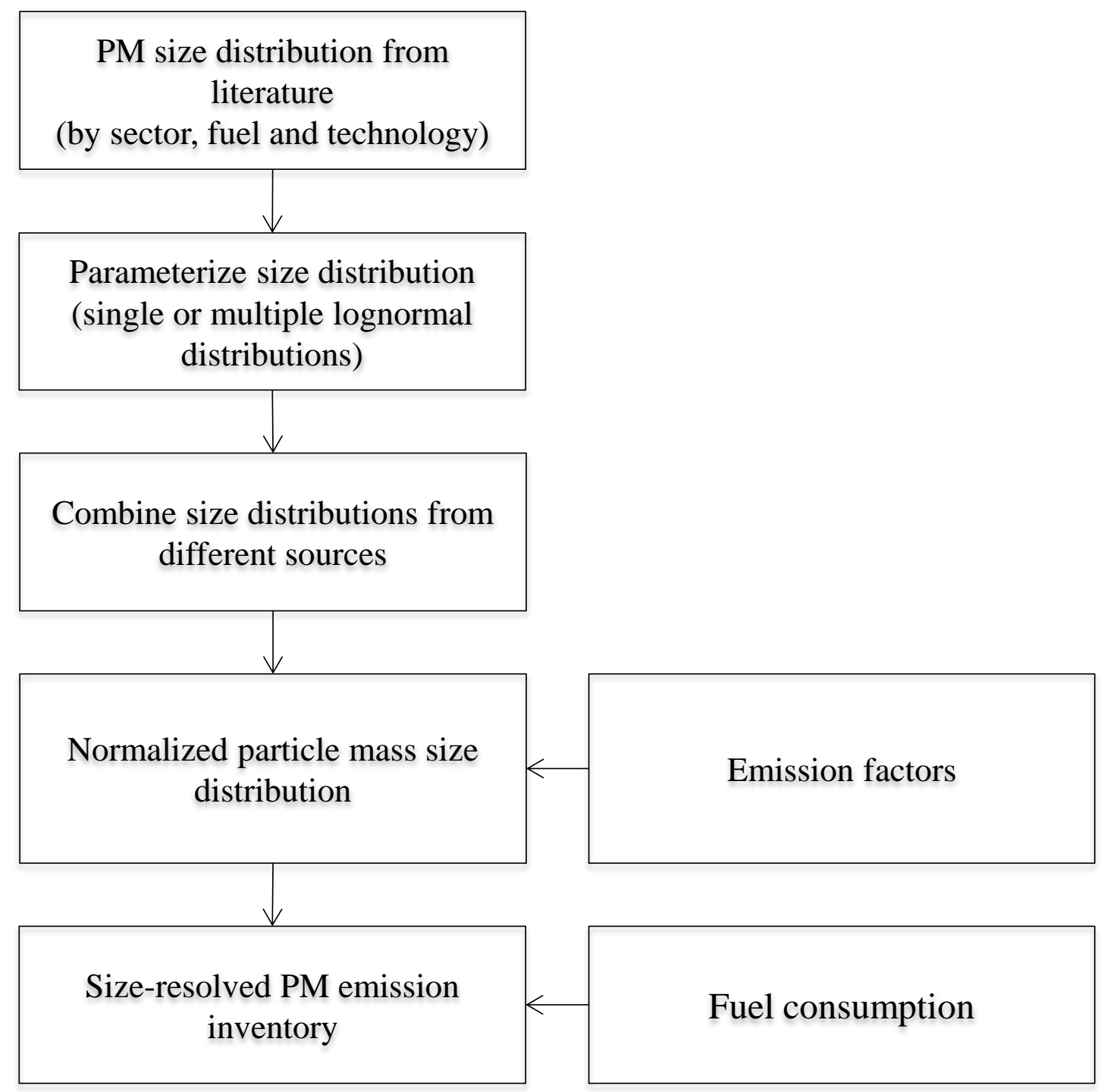

519 Fig. 1. Framework for building a size-resolved PM emission inventory. 

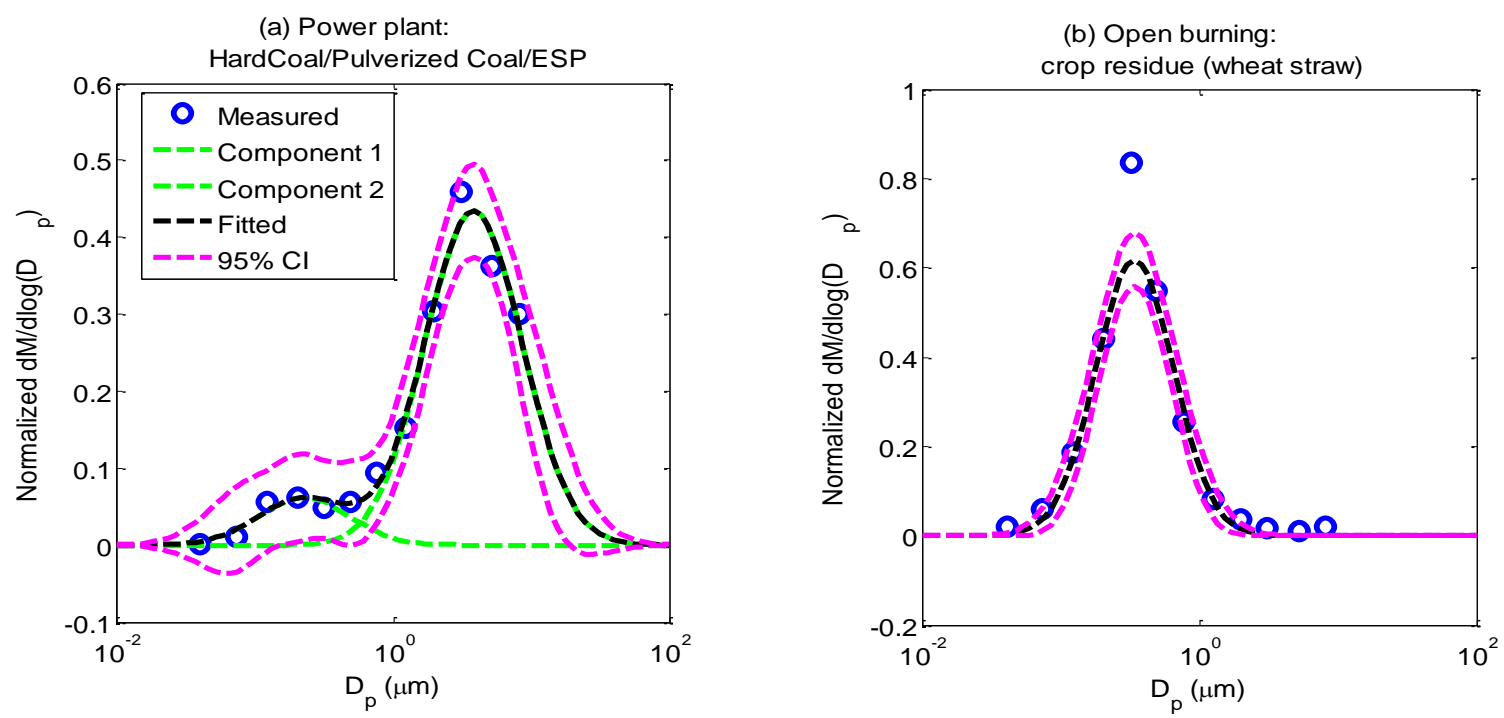

521 Fig. 2. Normalized particle size distribution by mass for: (a) power-plant boiler using pulverized 522 coal and ESP emission control; and (b) open burning of wheat straw. Measured data, fitted curve, 523 and 95\% CI are shown. Data sources: Zhao et al. (2010) and Li et al. (2007). 

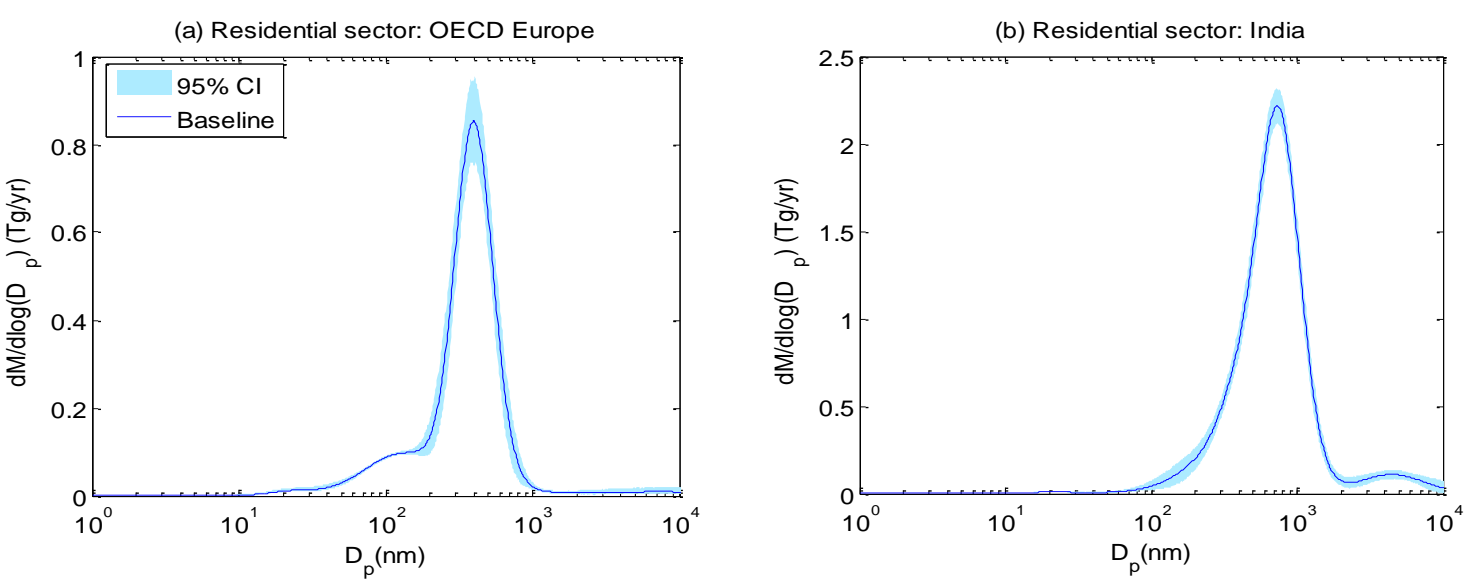

524

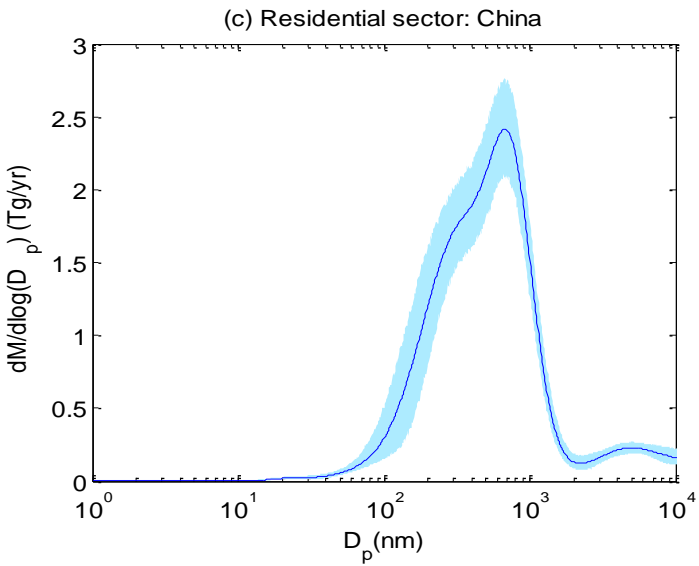

525

Fig. 3. Regional size-resolved $\mathrm{PM}_{10}$ emissions with $95 \% \mathrm{CI}$ for the residential sector for (a)

526 Fig. 3. Regional size-resolved $\mathrm{PM}_{10}$ em
527 OECD Europe, (b) India, and (c) China. 

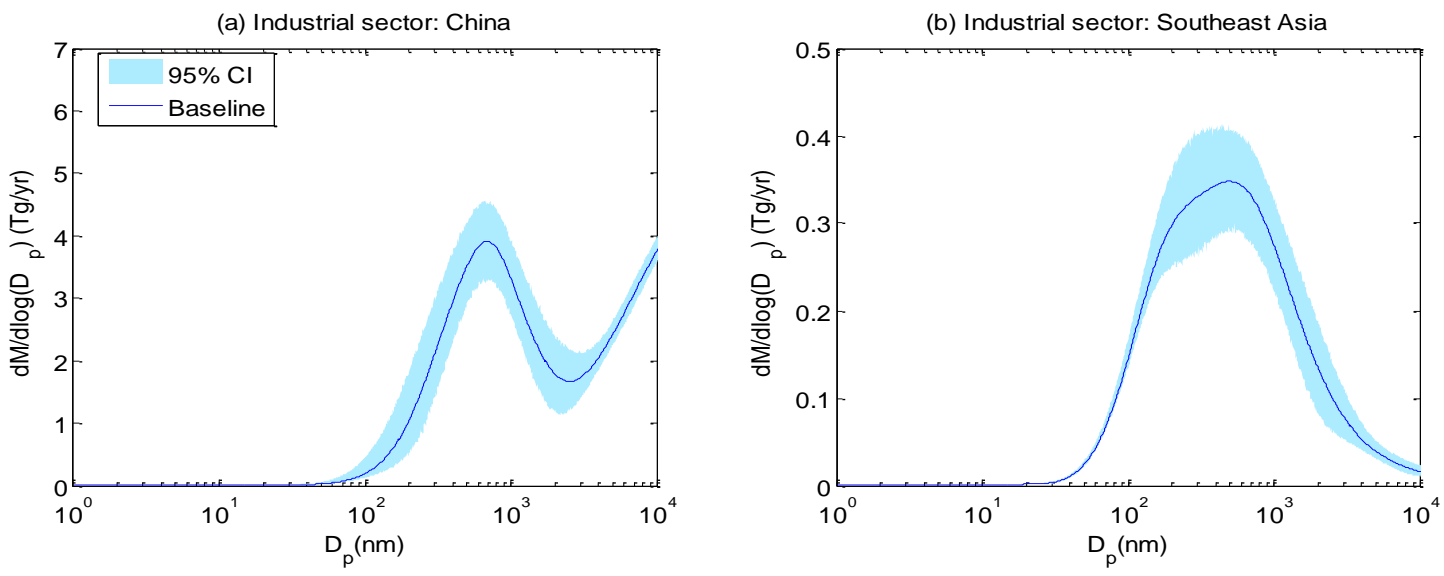

529 Fig. 4. Regional size-resolved $\mathrm{PM}_{10}$ emissions with 95\% CI for the industrial sector for (a)

530 China and (b) Southeast Asia. 

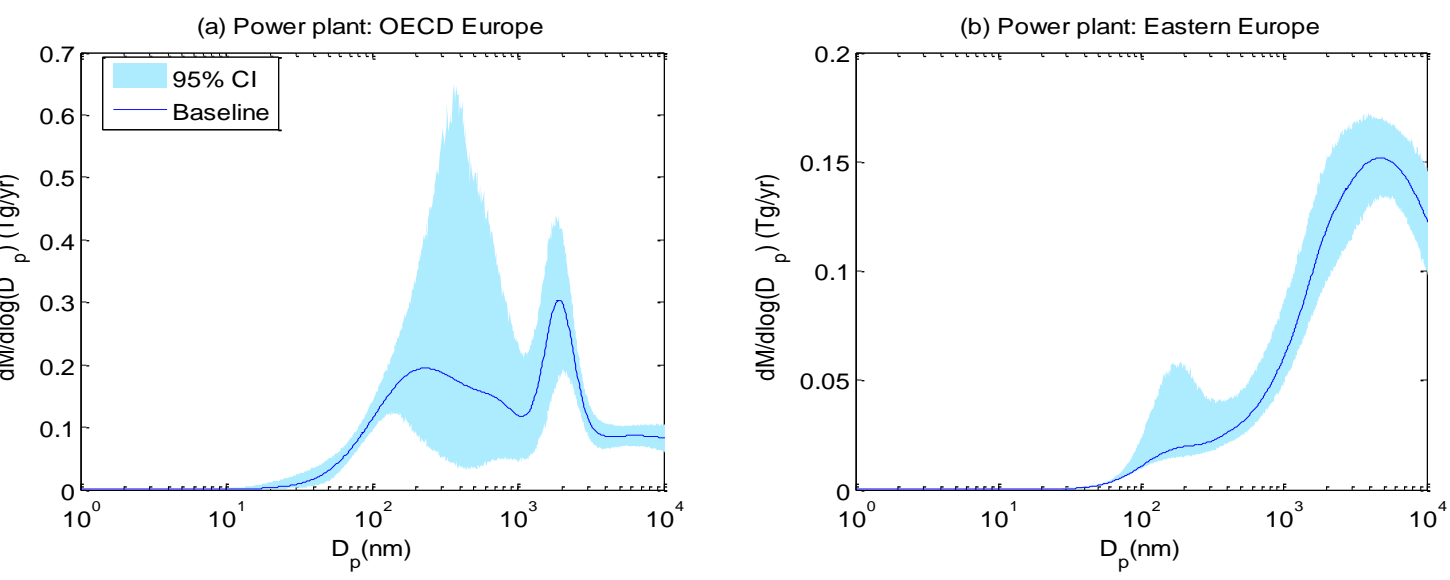

531

532 Fig. 5. Regional size-resolved $\mathrm{PM}_{10}$ emissions with $95 \% \mathrm{CI}$ for the power sector for (a) OECD

533 Europe and (b) Eastern Europe. 
(a) Transportation: USA

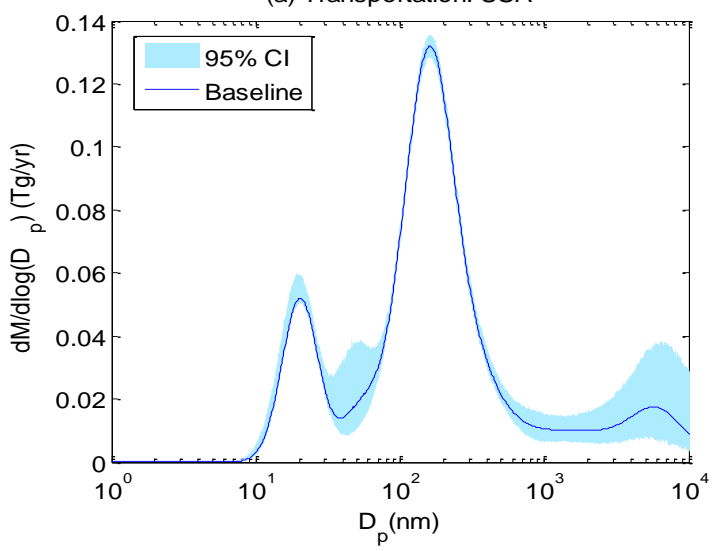

534

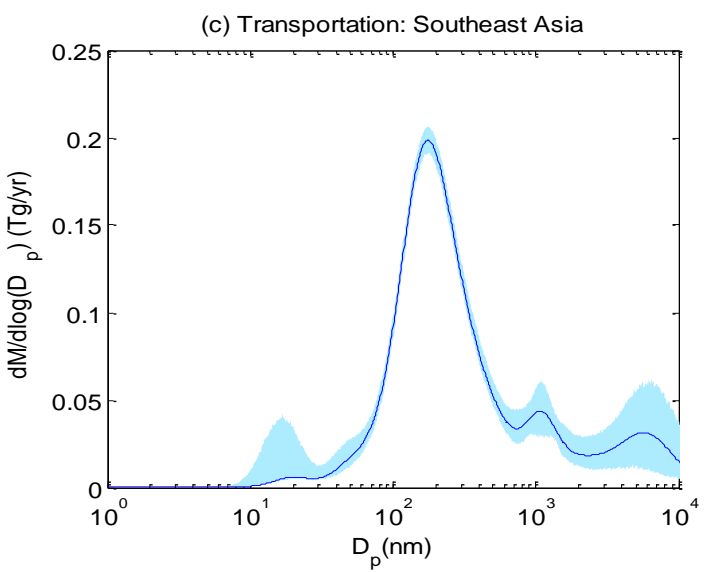

(b) Transportation: Southern Africa

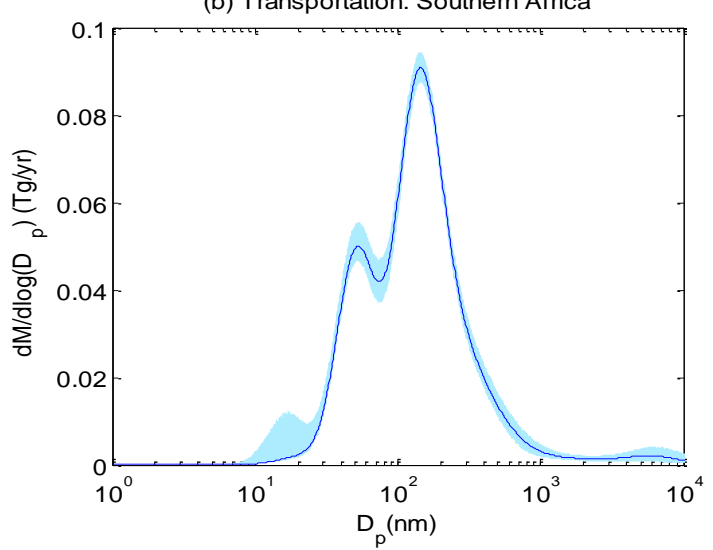

536 Fig. 6. Regional size-resolved $\mathrm{PM}_{10}$ emissions with $95 \%$ CI for the transportation sector for (a)

537 the U.S., (b) Southern Africa, and (c) Southeast Asia. 
538
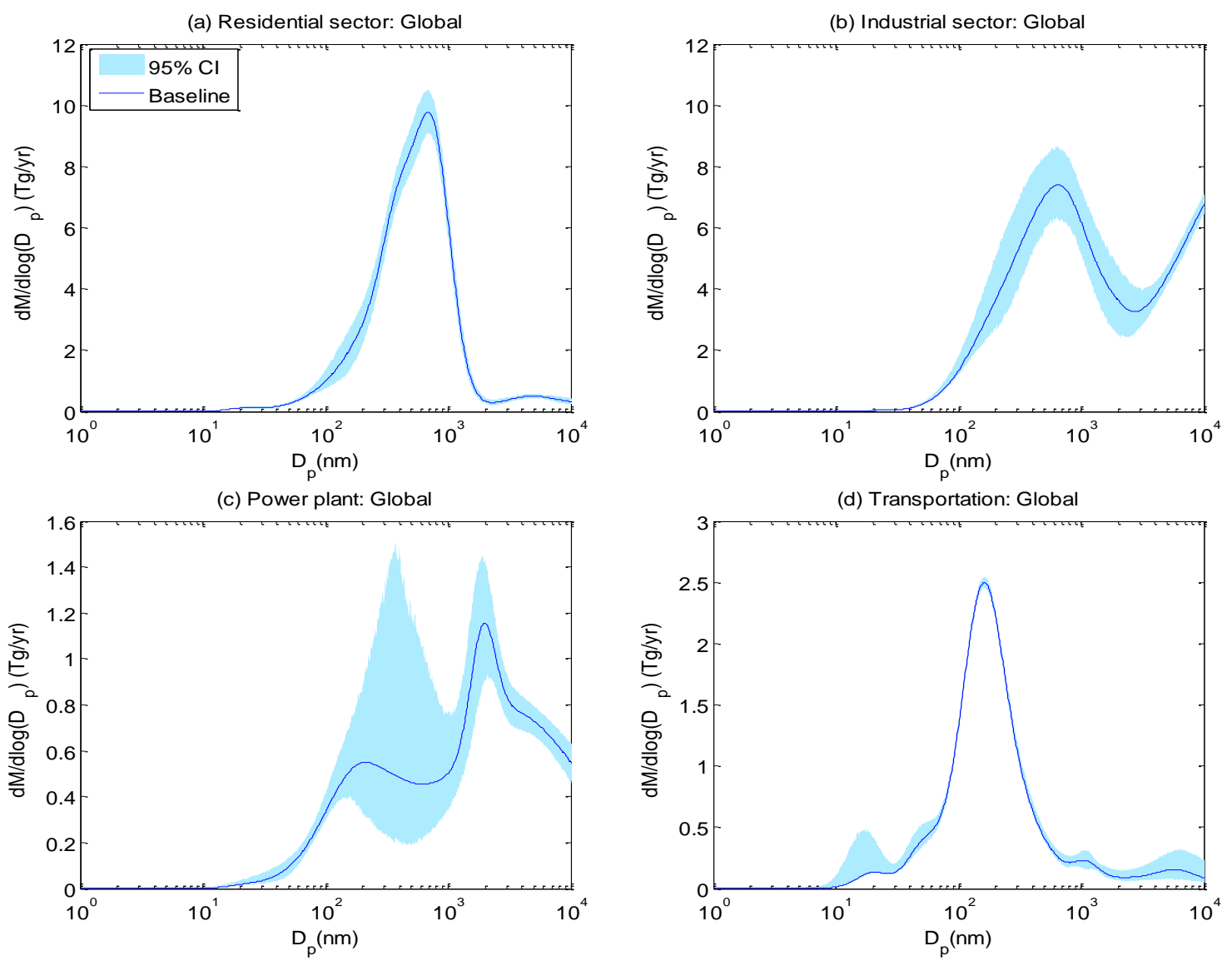

Fig. 7. Global size-resolved $\mathrm{PM}_{10}$ emissions with $95 \% \mathrm{CI}$ for (a) residential, (b) industrial, (c) power, and (d) transportation sectors. 
(a) Sectoral contribution

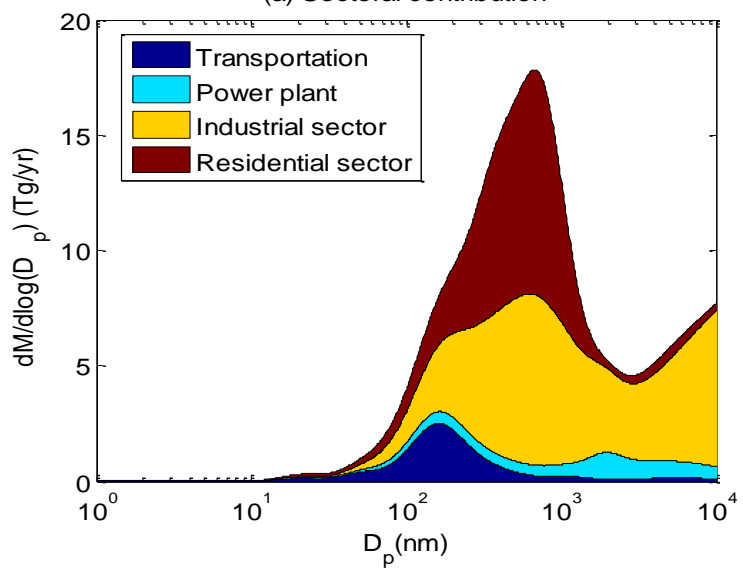

(b) Regional contribution

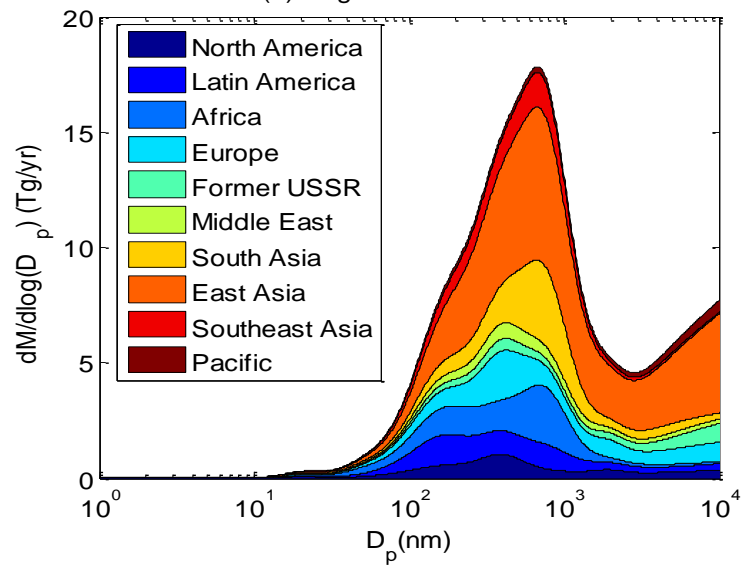

543 Fig. 8. Global size-resolved $\mathrm{PM}_{10}$ emissions for all energy-related combustion sources: (a)

544 emissions by sector; (b) emissions by major world region. 
(a) Residential sector: Global

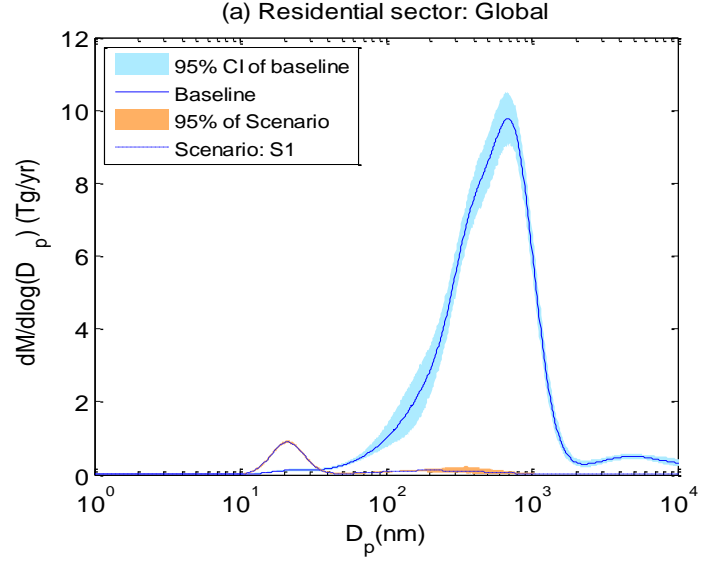

(c) Transportation: Global

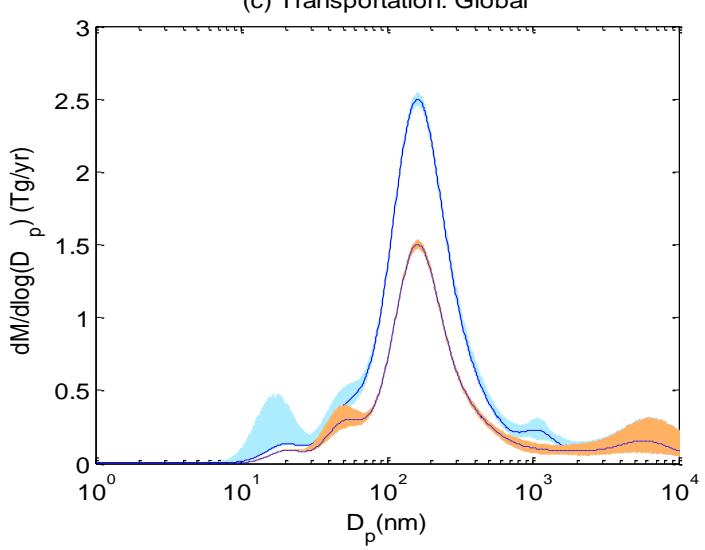

(b) Industrial sector: Global

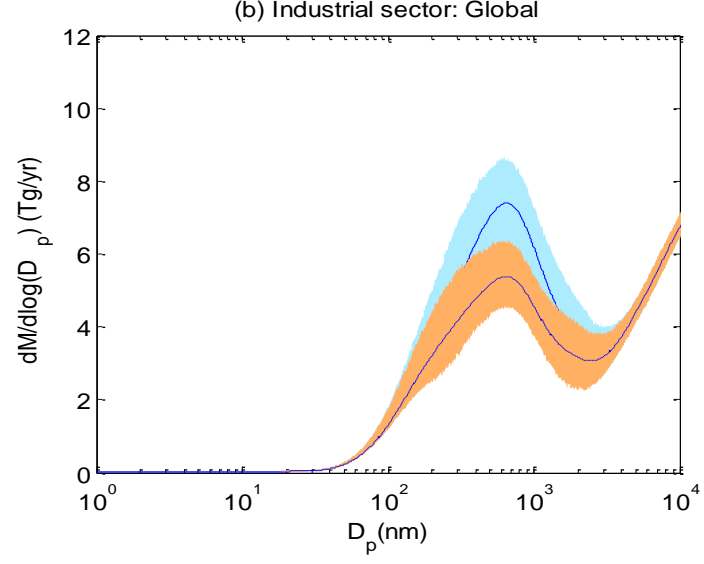

(d) All sectors: Global

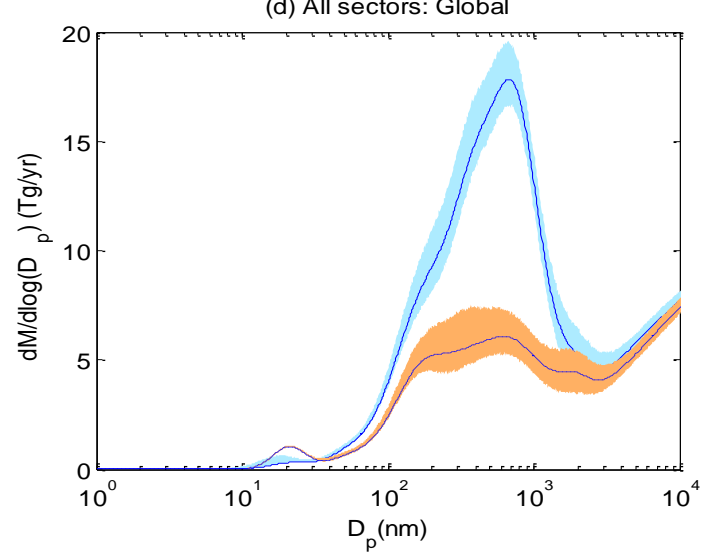

547 Fig. 9. Global size-resolved $\mathrm{PM}_{10}$ emissions under assumed emission control scenarios: (a) 548 clean household-fuels combustion scenario (S1), (b) controlled cement kiln scenario (S2), (c) 549 clean vehicle scenario (S3), and (d) all control scenarios combined $(\mathrm{S} 1+\mathrm{S} 2+\mathrm{S} 3)$. 
Tables

551 Table 1 Regional $\mathrm{PM}_{10}$ emissions in 2010 (Gg/yr)

\begin{tabular}{|c|c|c|c|c|c|c|c|}
\hline \multirow[b]{2}{*}{ Region } & \multicolumn{4}{|c|}{ Baseline } & \multicolumn{3}{|c|}{ Scenario } \\
\hline & Residential & Industry & Power & Transportation & $\begin{array}{l}\text { Residential } \\
\quad\left(\mathrm{S} 1^{\mathrm{a}}\right)\end{array}$ & $\begin{array}{l}\text { Industry } \\
\left(\mathrm{S} 2^{\mathrm{a}}\right)\end{array}$ & $\begin{array}{c}\text { Transportation } \\
\left(\mathrm{S}^{\mathrm{a}}\right)\end{array}$ \\
\hline Canada & 98 & 149 & 26 & 35 & 2 & 137 & 28 \\
\hline USA & 495 & 820 & 515 & 239 & 36 & 753 & 198 \\
\hline Central America & 372 & 334 & 61 & 339 & 22 & 283 & 270 \\
\hline South America & 396 & 1676 & 76 & 314 & 27 & 1566 & 113 \\
\hline Northern Africa & 39 & 366 & 11 & 233 & 10 & 270 & 124 \\
\hline Western Africa & 1559 & 344 & 3 & 102 & 90 & 321 & 78 \\
\hline Eastern Africa & 808 & 94 & 2 & 48 & 42 & 84 & 25 \\
\hline Southern Africa & 574 & 195 & 41 & 148 & 31 & 177 & 104 \\
\hline OECD Europe & 812 & 1332 & 762 & 334 & 56 & 1161 & 225 \\
\hline Eastern Europe & 472 & 401 & 356 & 80 & 12 & 357 & 35 \\
\hline Former USSR & 271 & 1154 & 227 & 174 & 28 & 1068 & 95 \\
\hline Middle East & 264 & 909 & 213 & 319 & 10 & 687 & 140 \\
\hline South Asia (no India) & 706 & 203 & 10 & 73 & 37 & 162 & 41 \\
\hline India & 2491 & 1411 & 107 & 169 & 126 & 1190 & 61 \\
\hline East Asia (no China) & 111 & 614 & 80 & 142 & 25 & 542 & 88 \\
\hline China & 4392 & 10672 & 380 & 551 & 188 & 8840 & 370 \\
\hline
\end{tabular}




\begin{tabular}{lrrrrrrr} 
Southeast Asia & 1535 & 976 & 67 & 347 & 70 & 817 & 209 \\
Oceania & 52 & 127 & 69 & 37 & 2 & 117 & 24 \\
Japan & 22 & 693 & 100 & 44 & 4 & 641 & 35 \\
World & 15471 & 22471 & 3107 & 3730 & 819 & 19174 \\
\hline
\end{tabular}

${ }^{\mathrm{a}} \mathrm{S} 1$ is the clean household-fuels combustion scenario; S2 is the controlled cement kiln scenario; S3 is the clean vehicle scenario. 
553 Table 2 Global and regional $\mathrm{PM}_{10}, \mathrm{PM}_{2.5-10}, \mathrm{PM}_{2.5}, \mathrm{PM}_{1-2.5}$, and $\mathrm{PM}_{1}$ emissions

\begin{tabular}{|c|c|c|c|c|c|}
\hline & $\mathrm{PM}_{10}$ & $\mathrm{PM}_{2.5-10}$ & $\mathrm{PM}_{2.5}$ & $\mathrm{PM}_{1-2.5}$ & $\mathrm{PM}_{1}$ \\
\hline \multicolumn{6}{|c|}{ Baseline Emissions (Gg/yr) } \\
\hline Residential Sector & 15471 & 588 & 14883 & 1593 & 13291 \\
\hline Industrial Sector & 22471 & 6386 & 16085 & 4016 & 12069 \\
\hline Power Sector & 3107 & 1014 & 2093 & 797 & 1296 \\
\hline Transportation Sector & 3730 & 173 & 3556 & 132 & 3425 \\
\hline \multicolumn{6}{|c|}{ Scenario Emissions $(\mathrm{Gg} / \mathrm{yr})$} \\
\hline Residential Sector $\left(\mathrm{S} 1^{\mathrm{a}}\right)$ & 819 & 1 & 818 & 8 & 811 \\
\hline Industrial Sector $\left(\mathrm{S} 2^{\mathrm{a}}\right)$ & 19174 & 6332 & 12843 & 3245 & 9597 \\
\hline Transportation Sector $\left(\mathrm{S}^{\mathrm{a}}\right)$ & 2263 & 172 & 2091 & 83 & 2009 \\
\hline \multicolumn{6}{|c|}{ Regional Contribution to Global Baseline Emissions (\%) } \\
\hline Canada & 0.7 & 0.7 & 0.7 & 0.4 & 0.8 \\
\hline USA & 4.6 & 4.1 & 4.7 & 4.2 & 4.9 \\
\hline Central America & 2.5 & 0.9 & 2.8 & 1.8 & 3.0 \\
\hline South America & 5.5 & 3.3 & 6.0 & 4.5 & 6.3 \\
\hline Northern Africa & 1.5 & 0.5 & 1.7 & 1.3 & 1.7 \\
\hline Western Africa & 4.5 & 0.4 & 5.4 & 3.5 & 5.8 \\
\hline Eastern Africa & 2.1 & 0.2 & 2.6 & 1.5 & 2.8 \\
\hline Southern Africa & 2.1 & 0.9 & 2.4 & 1.7 & 2.6 \\
\hline OECD Europe & 7.3 & 6.7 & 7.3 & 7.1 & 7.4 \\
\hline Eastern Europe & 2.9 & 4.8 & 2.5 & 2.7 & 2.5 \\
\hline Former USSR & 4.1 & 8.9 & 3.0 & 3.8 & 2.8 \\
\hline Middle East & 3.8 & 3.4 & 3.9 & 4.2 & 3.8 \\
\hline South Asia (no India) & 2.2 & 0.5 & 2.6 & 2.1 & 2.7 \\
\hline India & 9.3 & 5.6 & 10.1 & 10.1 & 10.2 \\
\hline East Asia (no China) & 2.1 & 3.7 & 1.8 & 2.3 & 1.6 \\
\hline China & 35.7 & 48.0 & 33.0 & 40.4 & 31.4 \\
\hline
\end{tabular}




$\begin{array}{llllll}\text { Southeast Asia } & 6.5 & 1.7 & 7.6 & 5.9 & 8.0 \\ \text { Oceania } & 0.7 & 0.9 & 0.6 & 0.6 & 0.6 \\ \text { Japan } & 1.9 & 4.8 & 1.3 & 1.9 & 1.1\end{array}$

$554{ }^{a} \mathrm{~S} 1$ is the clean household-fuels combustion scenario; S2 is the controlled cement kiln scenario; $555 \quad \mathrm{~S} 3$ is the clean vehicle scenario.

556 